\title{
Referaat
}

\section{Waar blijft het onderzoek?}

\section{Cook DA. The research we still are not do- ing: an agenda for the study of computer- based learning. Acad Med 2005;80:541-8.}

Elf jaar geleden schreef Friedman ${ }^{1}$ een artikel in Academic Medicine getiteld The research we should be doing over de (logische) onmogelijkheid om computer-based learning (CBL) op een wetenschappelijk verantwoorde manier te vergelijken met onderwijs waarin niet van computers gebruik wordt gemaakt. In zijn publicatie betoogde hij dat er in iedere onderzoekssituatie dermate veel verschillen zijn tussen onderwijs met en zonder computers dat het onmogelijk is om een goede controlegroep samen te stellen.

Friedman pleitte er daarom voor om, in plaats van toch pogingen te doen om verschillende 'media' (computer, papier, face-to-face situaties) met elkaar te vergelijken, te kiezen voor onderzoek naar het effect van CBL dat wel op wetenschappelijk verantwoorde wijze kan worden uitgevoerd. Dit onderzoek is mogelijk door vergelijkbare eigenschappen van verschillende CBL-programma's op een bepaald niveau met elkaar te vergelijken. Binnen een medium (in dit geval CBL) kunnen drie hiërarchische niveaus van instructioneel design worden onderscheiden:

1. Configuratie (bv. een discussieforum op het web, een web-based tutorial, een tutorial op cd-rom).

2. Instructiemethode (bv. self-assessmentvragen, simulaties, groepsdiscussies).

3. Presentatie (bv. hyperlinks, font, multimedia).

Vergelijkend onderzoek zou moeten worden verricht naar het effect van de verschillende mogelijkheden binnen een bepaald niveau in plaats van naar eigenschappen die tot verschillende niveaus horen; hierop doelde Friedman destijds met 'the research we should be doing'.
$\mathrm{Nu}$, in 2005, schrijft Cook in hetzelfde tijdschrift een artikel getiteld The research we still are not doing: an agenda for the study of computer-based learning. Het gebruik van computers in het medisch onderwijs heeft in de afgelopen elf jaar een enorme vlucht genomen, maar vergelijkend onderzoek naar het effect van CBL binnen een bepaald niveau van instructioneel design wordt nog steeds slechts mondjesmaat uitgevoerd, zo blijkt uit een inventarisatie van Cook. De auteur breekt opnieuw een lans voor dit type onderzoek en noemt bovendien een aantal extra onderzoeksvragen die zouden kunnen worden gesteld. Ondanks dit pleidooi voor een gedegen onderzoek naar het effect van CBL blijft Cook realistisch en beseft hij dat CBL geen panacee is voor alle educatieve problemen. In plaats van vooraf te besluiten om CBL te gaan gebruiken en dit vervolgens in het curriculum in te passen, zouden eerst de educatieve doelstellingen moeten worden bepaald en zou daarna pas moeten worden gekeken of CBL hier in past. Ook is het belangrijk te beseffen dat naast kortetermijncriteria, zoals de tevredenheid over het gebruik van CBL bij opleiders en studenten, langetermijncriteria zoals de uiteindelijke kwaliteit van de arts minstens zo belangrijk zijn.

Na lezing van dit artikel dringt zich automatisch de vraag op hoe de situatie er over nog eens elf jaar uit zal zien. Ongetwijfeld is het gebruik van computers in het medisch onderwijs nog vanzelfsprekender geworden dan nu al het geval is. Daarnaast is het zeker niet onwaarschijnlijk dat er tegen die tijd opnieuw een artikel in Academic Medicine zal verschijnen over onderzoek dat nog steeds niet verricht wordt...

\section{Ellen Easton}

UMC Utrecht

\section{Literatuur}

1. Friedman C. The research we should be doing. Acad Med 1994;69(6):455-7. 